Article

\title{
The Status Quo and Ways of STEAM Education Promoting China's Future Social Sustainable Development
}

\author{
Xingwei Wang ${ }^{1}$, Wenwen $\mathrm{Xu}^{2}$ and Liang Guo ${ }^{1, *(D)}$ \\ 1 School of Information and Control Engineering, China University of Petroleum (East China), \\ Qingdao 266580, Shandong, China; 13153286426@163.com \\ 2 School of Economic and Management, China University of Petroleum (East China), \\ Qingdao 266580, Shandong, China; 17805428064@163.com \\ * Correspondence: guoliang@upc.edu.cn
}

Received: 6 October 2018; Accepted: 19 November 2018; Published: 26 November 2018

check for updates

\begin{abstract}
In the process of future sustainable development, human society faces problems such as severe population load, economic transition, and a lack of educational measures. One of the root causes of these problems is the shortage of innovative talents. Therefore, how to cultivate learners with multidisciplinary integration and innovation ability is a key point that should be paid attention to when promoting the concept of quality education and coping with the future sustainable development process. This paper uses the questionnaire survey and literature analysis methods to analyze the development of many educational institutions with the Science, Technology, Engineering, Art, and Mathematics (STEAM) concept as the core in China since 2017. It is found that the existing STEAM educational institutions generally have the following problems: a lack of team composition, difficulty in independent research and development, single course content, and an insufficient validation of course effectiveness. In order to more effectively promote the sustainable development of China's future course, STEAM education institutions should focus on strengthening the following development strategies: gradient team building, continuous independent research and development, cutting-edge projects, mechanisms of curriculum transformation, and multi-angle course effectiveness verification.
\end{abstract}

Keywords: integrating innovative talents; STEAM; multi-dimensional status analysis; cultivating competitiveness

\section{Introduction}

At present, the sustainable development process of China faces three key issues: the lack of high-level talents, the pressure of economic transformation, and the difficulty of education reform. Therefore, China urgently requires high-level practical talents and innovative talents with knowledge and skills in the development process, but China's current talent training situation is out of line with this goal [1]. In order to solve the above problems fundamentally, a new model of talent cultivation that adapts to China's development is urgently needed.

However, the contradiction between the university's integrated talent training model and the industry's demand for innovative talents has becoming increasingly prominent [2]. Therefore, based on the spirit of promotion, a further step on advancing teaching and innovating education is urgently needed [3]. At this time, the emergence of Science, Technology, Engineering, Art, and Mathematics (STEAM) education is a timely assistance, providing new strategies and tools, and has gradually formed a trend in recent years with its unique curriculum concept, multidisciplinary integration teaching system, and teaching methods. 
With a multidisciplinary fusion feature, STEAM education focuses on cultivating students' innovative capability and engineering literacy. It has a great advantage in dealing with the three key issues stated above. The first is the population load. Based on the state's policy guidance at the population level, one of the key measures to reduce the population load is to improve the quality of the working population, especially the creative practical ability and information technology literacy [4]. Through the improvement of the quality of the population, the reduction of the population load on the transformation of the educational model is alleviated. The second is economic transformation. China is mainly faced with the problems of economic structure decline, the lack of an innovation economy, and difficulties in implementing ecological economy [5]. These problems are extremely complex and require a multidisciplinary knowledge system to be integrated, but China is in short supply of compound talent reserves [6]. The third is the lack of education. As mentioned above, although China has a large population, China is facing the challenge of a serious shortage of innovative talents. China's "13th Five-Year National Science and Technology Talent Development Plan" [7] released in April 2017 pointed out that it is estimated that the aerospace talent gap will be about 48,000, and the energy shortage and new energy automobile industry will have a talent gap of about 250,000 by 2025 . There will be a large supply gap for high-level talents, high-end research and development (R\&D) talents, and highly skilled talents in China's future science frontiers. This is probably because the current education model of China has some problems in cultivating innovative talents, which makes it difficult to produce top-notch innovative talents that can cope with the difficulties and challenges of future science and technology undertakings [8].

Based on the above analysis, it can be seen that the core main points of the three major problems of population, economy, and education that have been exposed in the current social development process in China include the lack of innovation ability, the lack of innovative talents, and the low scientific and technological literacy of a large number of industrial workers. Therefore, the introduction of an interdisciplinary innovation ability training model based on multidisciplinary integration is particularly important [9].

Although STEAM education is a national development strategy that was proposed by the United States to cope with future social challenges, because of the universality and applicability of the education model itself, STEAM education as an educational concept and education model has gradually evolved into the process of integrating Chinese education. Combined with the national conditions and characteristics of China's education development, it will be part of an educational model with Chinese characteristics.

STEAM education originated from Science, Technology, Engineering, and Mathematics (STEM) education, [10] which was originally proposed by the American University of Virginia scholar Yakman in the study of comprehensive education, whose purpose is to strengthen the United States (US) $\mathrm{K}-12$ education in science, technology, engineering, art, and mathematics [11]. STEM education was proposed fist; then, the cultivation of art and humanities literacy was gradually integrated into STEM education, which formed STEAM education [12]. STEAM education is receiving more and more attention in its development. The establishment of hands-on creative courses has gradually evolved into a national strategy for education in the United States. STEAM education is known as the "quality education" in the United States, so it has also received study and attention from all over the world [13]. At present, STEAM education has become the research hotspot of science education policy in many countries, and has been gradually applied in the science and technology education curriculum at the basic education stage [14].

Innovative talent is the key to the core competitiveness of the country. Although the United States ranks first in terms of comprehensive innovation capability, it still puts forward a STEAM education strategy that is committed to improving citizens' innovative practice. China has ushered in a rapid economic development since its reform and opening up in 1978, but there has been a huge gap in innovative talents. Therefore, China needs to learn from STEAM education in order to improve the literacy of its citizens [15]. With the integration of Chinese culture, STEAM education could help 
China reform and transform the dilemma regarding its innovative talents. In an effort to integrate STEAM education with Chinese culture, many Chinese scholars have conducted a lot of research and exploration. In 2007, the first article in China on STEAM education, "STEAM Strategy for American Education in the Age of Globalization", opened the prelude to the study of STEAM education in China. This article analyzes the reasons for the implementation of the STEAM strategy in the United States from the relevant bills and policies of STEAM. In 2013, the first translation of STEAM education in China was published.

At the same time, another mode of education is also known in China: the Maker education model. Maker education is a quality education model that emphasizes innovation and practice and is based on student interests, using project learning methods, advocating creation, and encouraging sharing. From the perspective of interdisciplinary innovation, there are many commonalities between Maker education and STEAM education, which can promote each other [16]. STEAM education has a close relationship with Maker education. Maker education provides a new and effective method for STEAM education, and STEAM education provides the knowledge and ability foundation for the cultivation of talents [17]. The integration of STEAM education and Maker education will comprehensively promote the cultivation of students' innovative ability and high-level thinking ability, develop advanced skills, establish a connection with real life, and make up for the lack of engineering education. [18] While analyzing the differences between them, the researchers also explained the necessity of the implementation of the STEAM concept in China. Through the investigation of the existing training institutions, it is found that STEAM education has encountered many problems in China due to the limitations in team, curriculum design, and curriculum effectiveness verification [19]. Although some important projects and institutions have emerged in China, they have fallen into a certain predicament more or less in the process of promoting STEAM education. Thus, what is the current status of the development of STEAM educational institutions in China? What kind of development trend will there be in the future? What is the way to solve the dilemma of existing problems? These issues deserve attention.

Based on the statistical analysis data of the more than 1000+ STEAM educational institutions conducted by the United Intelligence Times Big Data Analysis Company, this study has carried out an in-depth analysis and resolution of the above three major problems. Combined with the current situation of the implementation of STEAM education in China and the problems faced by STEAM teaching at the present stage, this paper proposes strategies and approaches for the promotion and development of STEAM teaching in China.

\section{Conception and Materials}

STEM (Science, Technology, Engineering, and Mathematics) education, which has aroused widespread concern around the world, originated from the "integrated" national development strategy proposed by the National Science Council in 1986 to address the challenges of future social development [20]. Through a literature search, we can find that the first STEM education translation, "The STEM Project Student Research Handbook" was published in 2013. Since then, Zhao Zhongjian's team has translated and published many related works, such as "The Integration of Engineering and Science in the Classroom", "Design, Production, and Games: Cultivating the Next Generation of STEM Innovators", and "Project-Based STEM Learning: A Way to Integrate Science, Technology, Engineering, and Mathematics" in 2015 [21]. He is also responsible for the selection of the "STEM Education Policy Progress in the United States".

With the continuous development of education, STEM education gradually joined the humanities, art, society, and other elements to evolve into STEAM education. STEAM education takes project learning as the main learning method. This is a new educational model based on STEM education. It is a fusion of technology and engineering education and artistic humanities education, aiming to promote technology-driven teaching innovation [22]. In recent years, China has introduced the STEAM concept to cultivate and integrate innovative talents, and has gradually become a fashion. A survey conducted 
by Georgette Yakman, who is the founding researcher of linking the subjects together to categorize the arts and contextualize STEM in the liberal arts fields formally backing the STEAM movement, shows that STEAM education has a more efficient performance in terms of creativity and participation in literacy. The integration of "Art" and STEM has further promoted the cultivation of learners' ability [23]. STEAM teaching focuses on the cultivation of students' practical skills while integrating knowledge of multidisciplinary courses. Unlike previous courses designed by teachers, it is a learner-centered, comprehensive approach to design and problem solving, emphasizing scientific inquiry, engineering design, and problem-based open learning, which can promote students' enthusiasm for learning. To further understand the characteristics of the STEAM concept and its advantages in promoting the future of China, this paper summarizes the STEAM literacy and curriculum types, the relationship between various disciplines, and the specific teaching implementation process by summarizing the research results in the field of STEAM at the present stage (Figure 1).

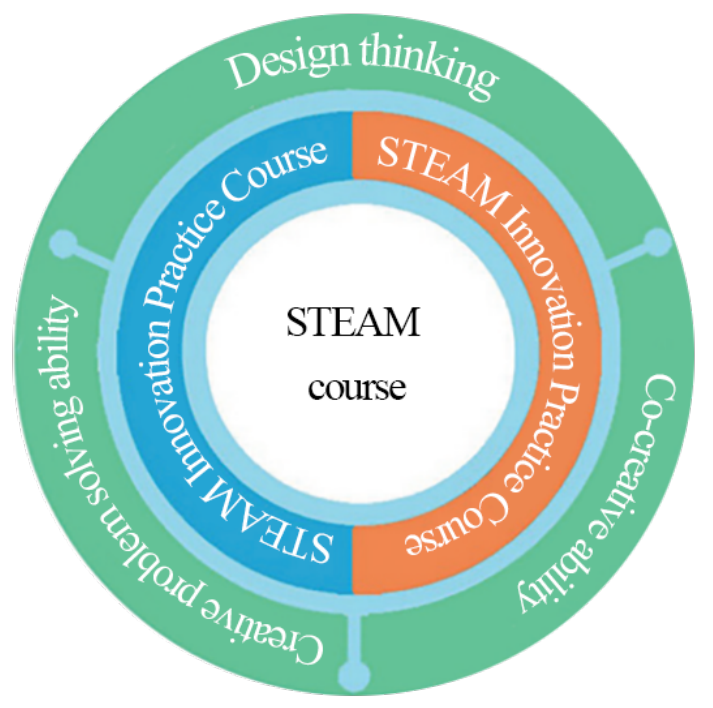

Figure 1. Science, Technology, Engineering, Art, and Mathematics (STEAM) literacy and course type.

The goal of curriculum reform in the basic education stage of China is to promote the comprehensive and individual development of students through the construction of the curriculum system and the curriculum platform. At this stage, most schools are based on basic courses, extended courses, and research courses [24], and the school curriculum is combined with national fixed courses and local courses to form their own independent curriculum system [25]. At present, the curriculum reform of the school is to integrate innovative literacy training on the basis of retaining the original curriculum knowledge system to meet the needs of sustainable development talents. From this perspective, this paper summarizes two forms of the STEAM curriculum when entering the school curriculum system: the STEAM Innovation Practice Course, and the STEAM Subject Practice Course.

(1) By drawing on Zhou Haiwei's research findings in the practice and exploration of general education research, the STEAM Innovation Practice Course can be described as an independent course, belonging to research, innovation, or specialty courses [26]. Different from emphasizing the independent status of physics, chemistry, mathematics, engineering, et al., it completely breaks the boundaries between disciplines, and uses the STEAM concept [27] to integrate the content of each subject around different themes into a new unified learning. In the field, an independent course learning unit is formed. In the learning of the course, the engineering design project is the core of its learning, and the creative products designed by the students are used as the basis for evaluation.

(2) The STEAM subject practice course is based on the national curriculum and belongs to the subject expansion course [28]. The difference from the STEAM Innovative Practice Course is that its 
subjects are courses in physics, chemistry, mathematics, biology, etc. It is based on a subject that is linked to other subject content, methods, tools, etc. through unit themes to achieve the purpose of student STEAM study [29].

By analyzing the purpose of STEAM education and combing the relationship among various disciplines, STEAM education is proposed to solve the problems and challenges presented by the real world, so the following relationships should exist between the various disciplines (Figure 2).

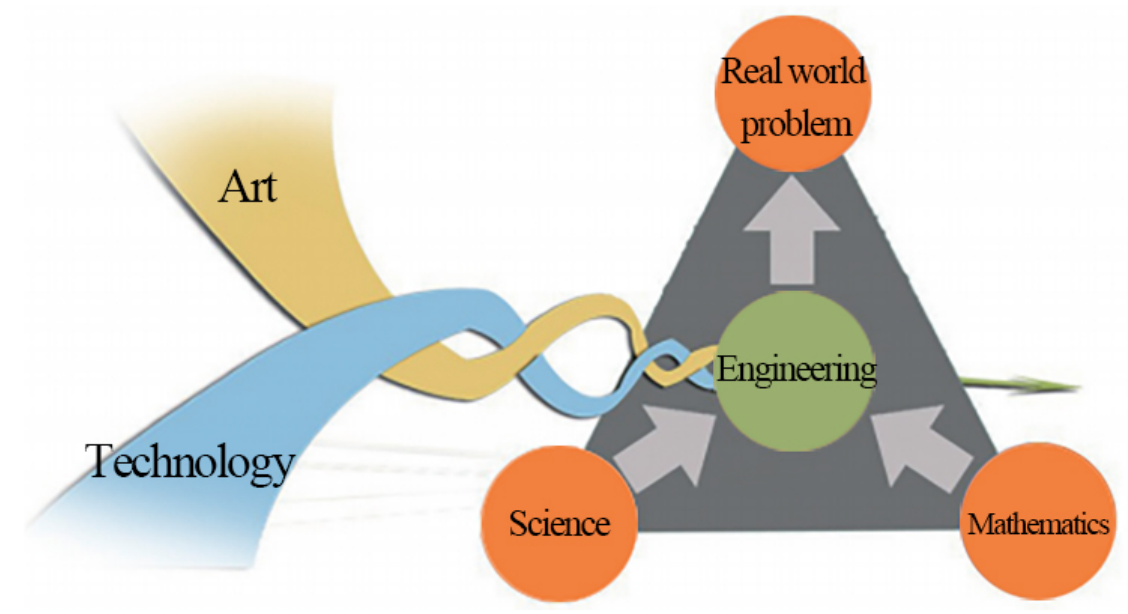

Figure 2. The various disciplines in STEAM education. Data Source: http://www.sohu.com/a/ 159249593_778222 International Education in China.

The relationships feature engineering as the core, science and mathematics as the foundation, and art and technology as aids, ultimately achieving the goal of driving the integration of various disciplines.

Since the STEAM course does not advocate a highly structured instructional classroom designed by the instructor, it is a learner-centered, integrated design and problem-solving curriculum. Therefore, based on the theoretical study of curriculum design, we expanded the SCS teaching method (Story-Copy-State-Copy Extended-Stimulate-Cooperation-Share) and the Mixly's "Home"-themed creative e-courses design, Lego Scratch programming courses, Shark Park dinosaur theme courses design, and other typical corporate cases to the analysis and summary of the course's design; as a result, this paper proposes the following specific teaching implementation process (Figure 3).
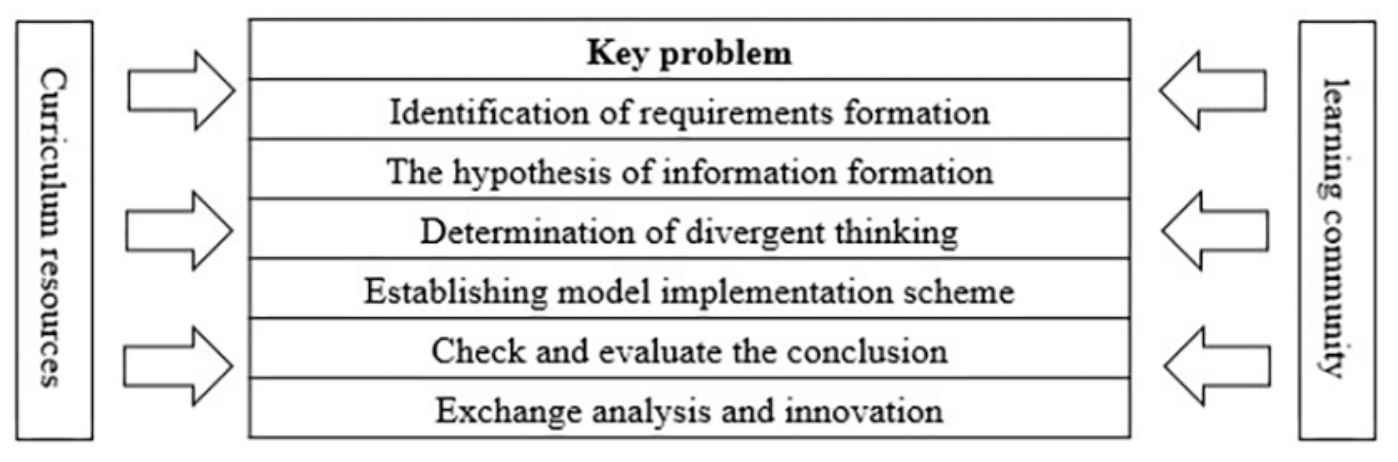

Figure 3. Teaching implementation process.

This process is a comprehensive part of teaching implementation, and does not involve the detailed issues of multiple disciplines in the course case. When arranging teaching, the teacher should systematically think about what to do (the purpose of the activity), how to do it (equipment, elements and materials, etc.) and what effect it has (what the student has discovered and what he has gained). 
Combining the types of courses, the relationship between disciplines, and the analysis of the specific teaching implementation process, the STEAM concept fusion innovation curriculum model formed by taking the dinosaur course as an example is shown below (Figure 4).
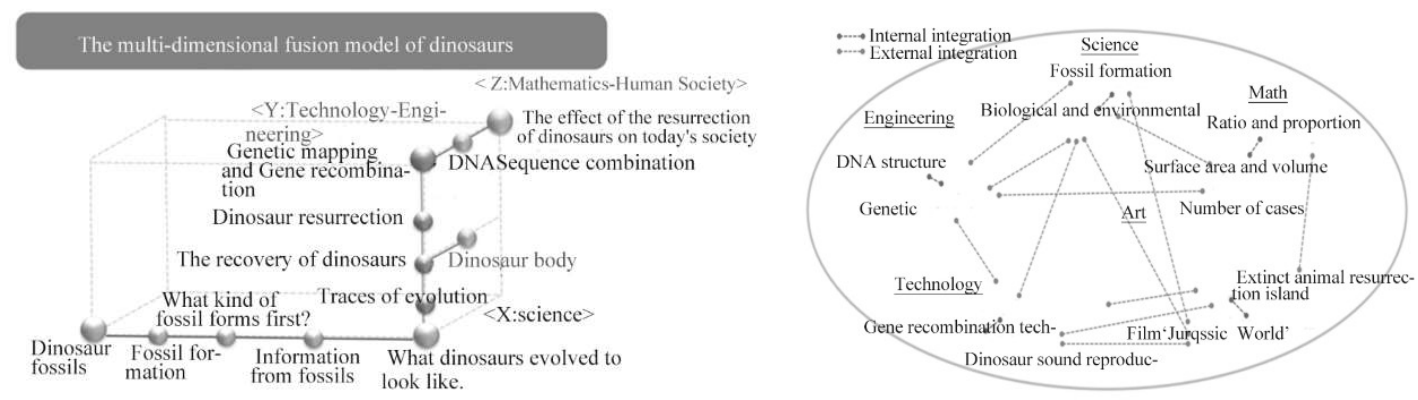

Figure 4. Actual course design display.

Through curriculum design examples and practical teaching, students are given the opportunity to apply scientific inquiry, engineering design, and problem-based, project-based learning methods to actively participate in real-world work practices. It proves that this is the main task of cultivating students' problem-solving ability and innovative ability rather than unilaterally imparting knowledge, and is in line with the training requirements for innovative talents in China's sustainable development process. At the same time, combined with China's national conditions, we can see the important role of cultural quality training in the entire education and training process [30]. Not only that, the use of artificial intelligence technology in the field of education has become more and more extensive with the development of the society. Whether it is big data analysis prediction or image recognition and capturing a learning state, it reflects the technological innovation to achieve learner-centered education. The huge push is generated by the goal. Therefore, on the basis of the STEAM concept, more attention should be paid to the impact of art and technology to better cultivate future talents that meet the needs of China's talent strategy.

\section{Results}

\subsection{The Practical Role of the STEAM Concept in the Future Process}

Along with the baptism of the second machine age revolution, people's daily behaviors are strongly challenged by information explosion and fissile brain growth [31]. In order to prepare for the rainy day, we must actively seek to cope with the strategy of revitalizing the country and the nation. Since the introduction of STEM education in China in 2007, after more than 10 years of research and practice, its connotation has been continuously enriched and interpreted, and it has gradually evolved into STEM+ and STEAM education, which are suitable for China's national conditions. Although some achievements have been made and a certain foundation has been laid, it is even more difficult to relax. It is necessary to clearly understand the shortcomings in the current STEAM education in China, and clarify the future development direction of STEAM education.

Under the influence of the new world, new literacy, and new education trends, the concept of integrated innovation education plays an important role in the future talent training. As we all know, the new world has brought about a new industrial revolution that can dramatically change the curve of human history. While providing new impetus and means for the advancement of the human civilization process, it also brings social development into a stage driven by technological innovation. The origin of the fourth industrial revolution was the "Industry 4.0 Strategy" that was first introduced by Germany in 2013 [32]. In 2015, China also issued the first 10-year action plan "Made in China 2025" to implement the strategy of manufacturing a strong country [33]. When the founder of the World Economic Forum, Klaus Schwab, spoke about the industrial revolution [34], unlike the revolution in the steam, electrification, and information ages, the fourth revolution regarded numbers and rationality. 
The interactive integration of various fields such as chemistry and health will not cause multiple challenges such as energy, ecological environment, and climate change. This revolution not only has intelligent interconnected machines, it has also created breakthroughs and innovations in many fields such as gene sequencing, nanotechnology, renewable energy, and quantum computing [35], which has made the entire social system enter high-speed development. At this stage, the relationship between technology and human symbiosis has been unprecedented. It can be said that the fourth industrial revolution not only brought about tremendous changes in human life, but also triggered a change in the ways that human beings live and the structure of the social industry; as a result, the demand for talents in the future will also change.

China is also actively responding to the future process, and in 2015, the country introduced the first 10-year action plan "Made in China 2025" on the implementation of the strategy of manufacturing a strong country. At the same time, it can be seen from the statistics of the growth rate of China mobile internet users that with the rapid development of artificial intelligence technology, the way of human survival has begun to move from network to intelligence (Figure 5).

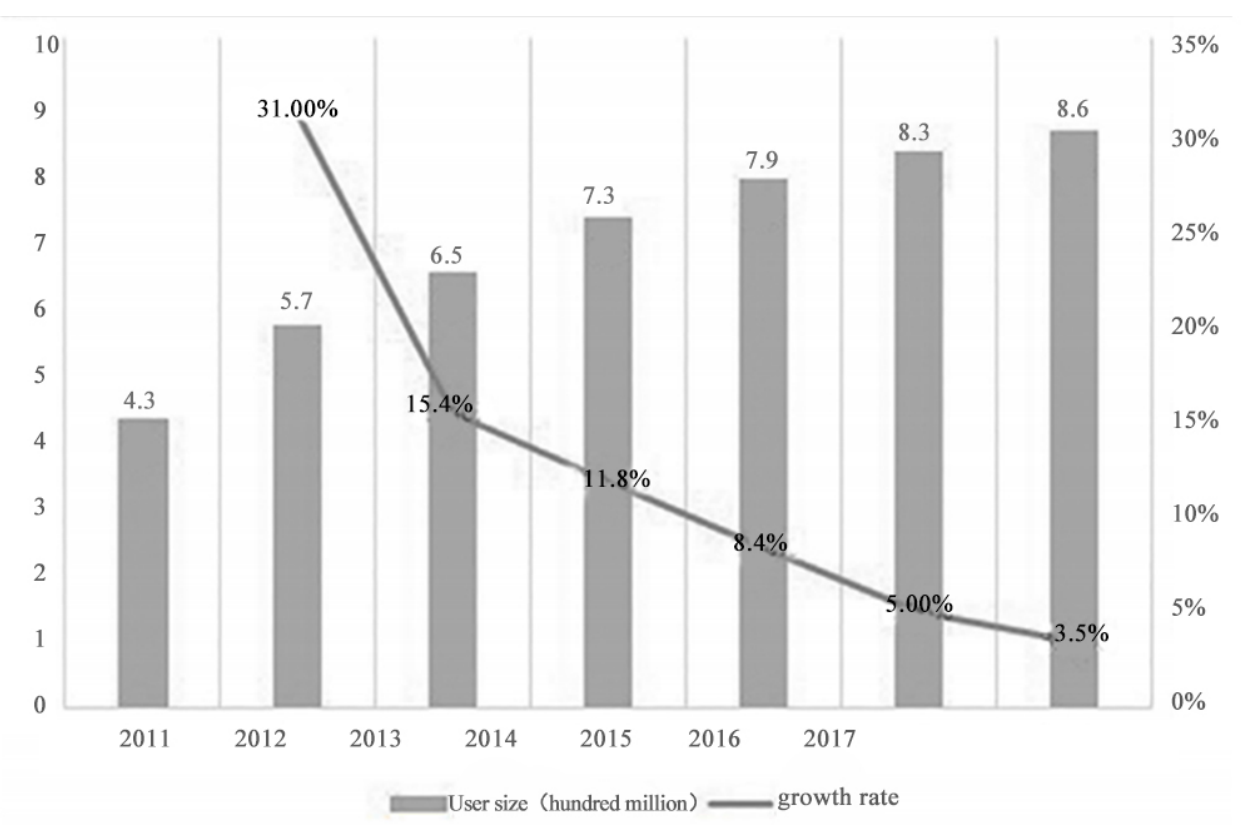

Figure 5. Internet user size and growth rate statistics. Data source: https://wenku.baidu.com/view/ 4867e8f9cfc789eb162dc83e.html (Analysis think tank).

At the same time, the deeper digital technology and the higher degree of integration brought about by the development of the New World have also triggered the transformation of the social industry structure. Through Klaus Schwab's research on adapting to the talents of the future society, it can be seen that by 2020, people with complex problem-solving skills, excellent social skills, and integrated system skills will have more room and opportunity for development (Figure 6). 


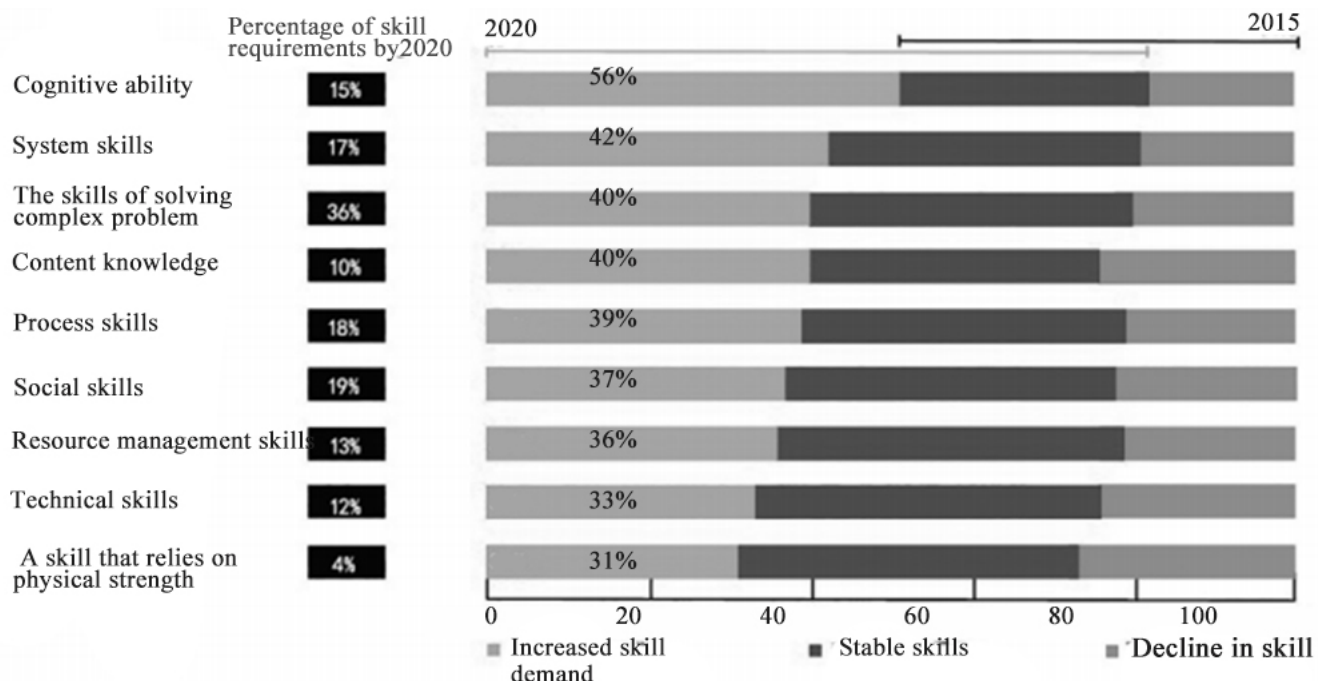

Figure 6. Statistic analysis of 2020 skills needs. Data source: The Future of Jobs: Employment, Skills, and Workforce Strategy for the Fourth Industrial Revolution, 2016.

What's more, it can be seen from the statistics on the job growth rate related to STEAM in professional recruitment that the market has a large demand for STEAM talents (Figure 7).

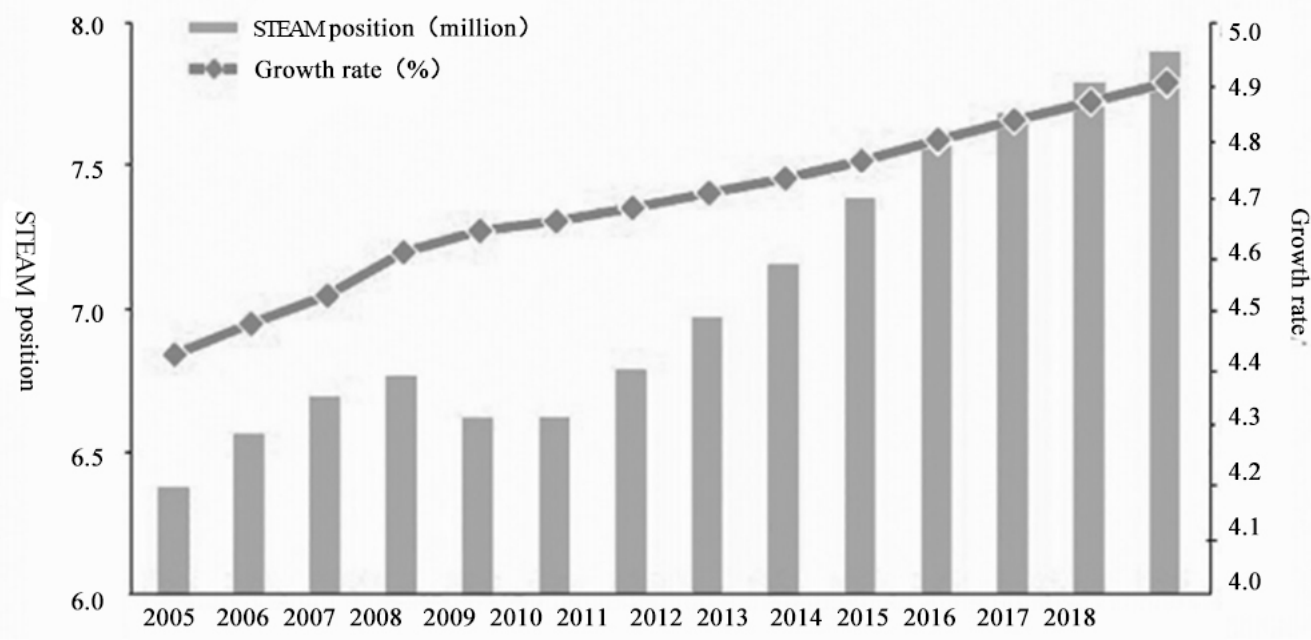

Figure 7. Growth rate of STEAM-related positions.

Through statistical analysis based on market data, it can be clearly seen that in the face of the rapid advancement of the sustainable development process in the future, China urgently needs a large number of composite talents with knowledge in science, engineering, art, mathematics, and other multidisciplinary fields to join the national construction [36]. Nowadays, the demand for single-skilled talents such as skilled workers in the first industrial revolution and electrical automation in the second industrial revolution has gradually decreased. The future sustainable development process brings revolutionary breakthroughs and innovations in various technologies based on information technology. This shows that to a certain extent, human thinking and problem-solving methods will change greatly. In order to comply with the trend of the future sustainable development process, the society needs more integrated innovative talents to apply valuable scientific and technological innovations that will promote the development of emerging technologies such as artificial intelligence and virtual reality. In turn, these advancements will promote the improvement of interdisciplinary results such as artificial organs and gene sequencing [37]. Based on the demand of social development for innovative talents, 
it is important to change the training mode and export of talents at this stage, and this is the core value of the STEAM concept.

The core element of science and technology as a production tool has also changed the ways that people live and the social structure of society while promoting the arrival of the four industrial revolutions. Therefore, the demand for talent type in the future social sustainable development process has also changed with these changes. This kind of change directly puts higher demands on the talent training strategies of various countries. The education of each country has begun to pay more attention to cultivating innovative talents with national responsibility, innovative thinking, and scientific and humanistic qualities [38]. According to the OECD 21st Century Student Core Literacy Training System and the analysis of the European Union (EU)'s lifelong learning eight literacies (use native language communication, use foreign language communication, mathematics literacy, basic scientific and technical literacy, digital literacy, learning ability, social and citizen literacy, self-awareness and entrepreneurial spirit, cultural cognition, and expression), this coincides with the STEAM concept [39].

Throughout the core literacy content developed by international organizations and different countries, when predicting the key competencies and essential characters that students should have when facing the challenges of the future, they basically pay attention to social responsibility, cooperation, exchange, and creative solutions to problems. China emphasizes the scientific spirit and humanistic heritage in the cultural fundamental field. These are the foundation for the comprehensive development of people and the core goal of STEAM education. Education is a future-oriented business, so when new challenges strike, as the main battlefield for talent training, more changes need to be made as the future talent needs change. American educator John Dewey once said: "If we still use the education of yesterday to train today's children, then we are depriving them of tomorrow."

\subsection{Multidimensional Analysis of the Status Quo of STEAM Educational Institutions}

Through cooperating with the Intelligence Times Big Data Analysis Company to analyze the sources of training content used by more than 1000+ STEAM educational institutions, we found that only $22.88 \%$ of institutions are able to conduct the research and development of teaching materials completely independently, and $60 \%$ of the institutions feature external procurement. Furthermore, with the combination of independent research and development, most institutions do not have the ability to independently develop courses. The data includes "The 2016-2017 China Education Industry Blue Book" (Figure 8).

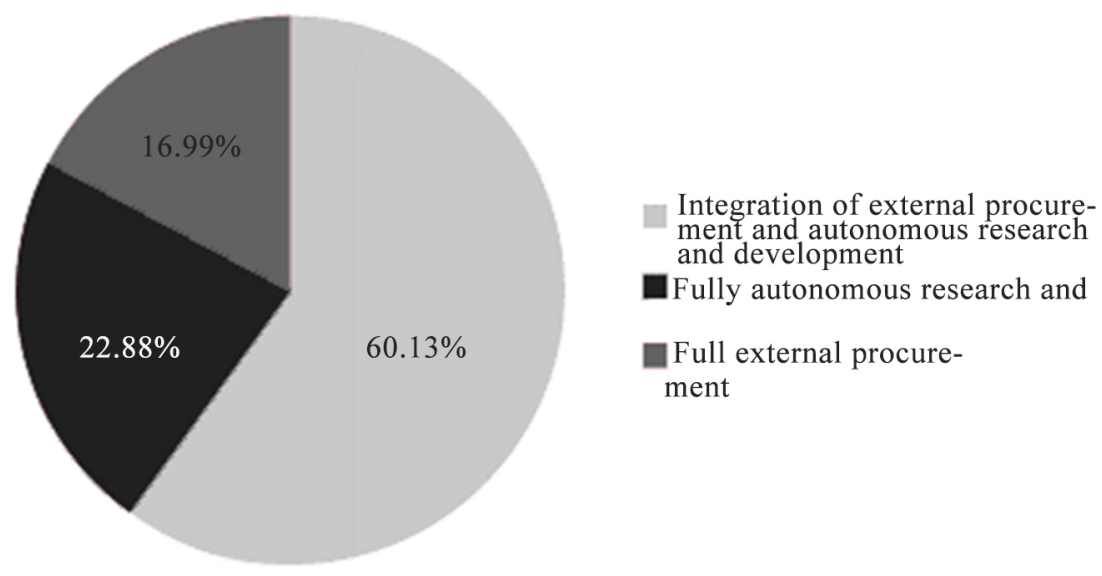

Figure 8. Source of teaching materials used by institutions.

Although the country has actively promoted the reform of exam-oriented education in recent years and strived to create a good policy environment for the development of STEAM education, the implementation speed of STEAM education in China is still slow. In recent years, the state has created a good policy environment for the development of STEAM education, and actively promoted 
education reform. However, due to the sluggish reform of China's education system, the STEAM education cognition concept is not uniform, the hardware is uneven, and the software content is lacking in curriculum content; thus, it is difficult for public schools to implement STEAM innovation education. Therefore, the implementation of STEAM in China is relatively slow.

At the user level, a large number of people born between $80-90$ years ago have entered the parent community; the characteristics of the user group have changed. Most parents with higher education have a new perspective on child growth. It can be seen from the " 2017 China Family Quality Education Consumption Report" that more than $60 \%$ of families are willing to invest more than 10,000 yuan in children's quality education every year. What's more, the ever-increasing consumer demand has made innovation education more popular. According to statistics, the growth rate of China's quality education market in 2017 was as high as 30\%. At the same time, with the upgrading of family education consumption, $80 \%$ of parents are willing to support children's extracurricular learning, and their investment in quality education and interest education has increased significantly.

By counting the 2017 consumer search keywords, the "creator" search heat map in the country was formed, and it was found that the word "creator" has the highest retrieval in the eastern coastal areas and first-tier cities such as Shanghai, Guangdong, and Beijing. The search ability of new first-tier cities such as Qingdao and Hangzhou is also relatively high. This shows that people's concepts have changed with the development of first-line developed cities. The recognition of STEAM education and robot education is steadily improving, and there is a huge potential user group (Figure 9).

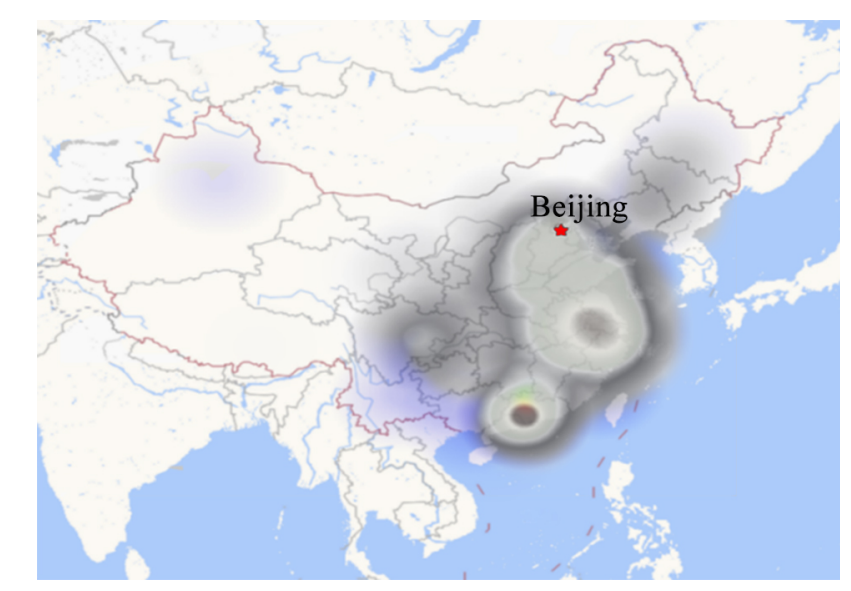

Figure 9. “Creator Education” 2017 consumer retrieval national regional thermal map.

Through statistics on consumers on personal computers (PCs) and mobile phones, respectively, from 2016 to 2017, consumers' attention to "robots" continues to increase, and cloud statistics on the PC side can also find that virtual reality (VR), robots, three-dimensional (3D) printing, and the like all maintain a high frequency of occurrence (Figure 10). 

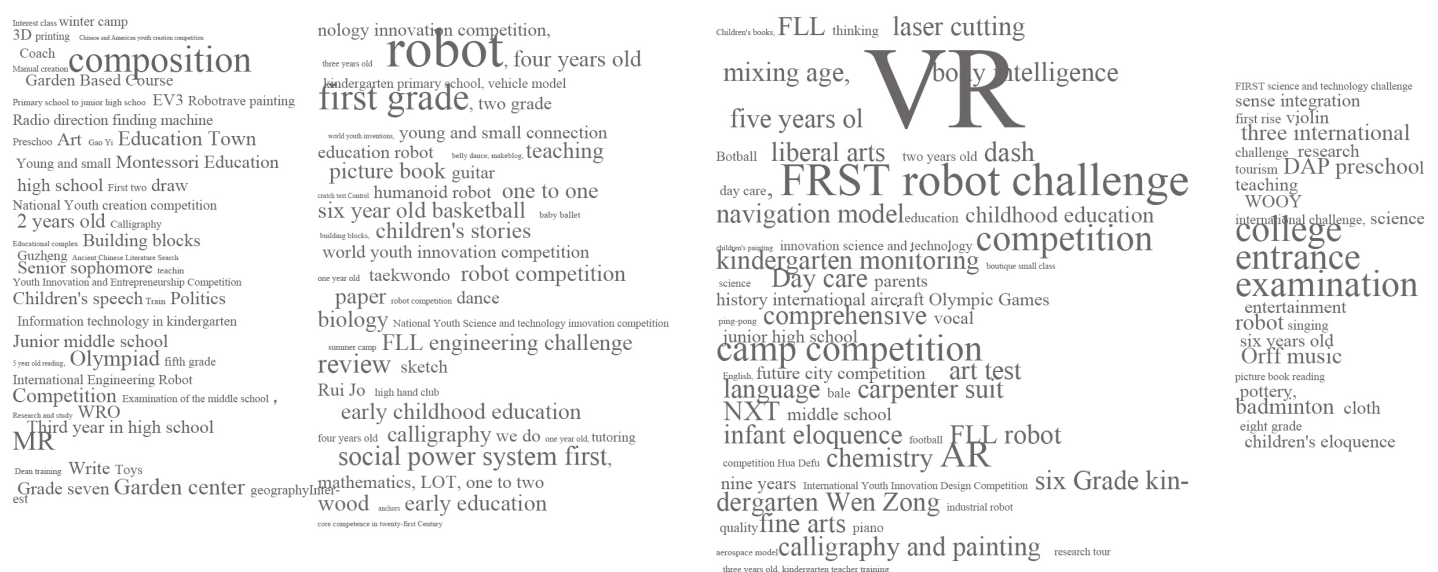

Figure 10. Consumer personal computer (PC)-side product attention word statistics. Data resource: “2016-2017 China Education and Training Industry Blue Book”, Zhilai Times.

In the 2016-2017 related education policy news, early childhood education, online education, family education, etc., have had a large increase, especially early childhood education (Figure 11).

2016-2017 Statistical breakdown of educational policy information

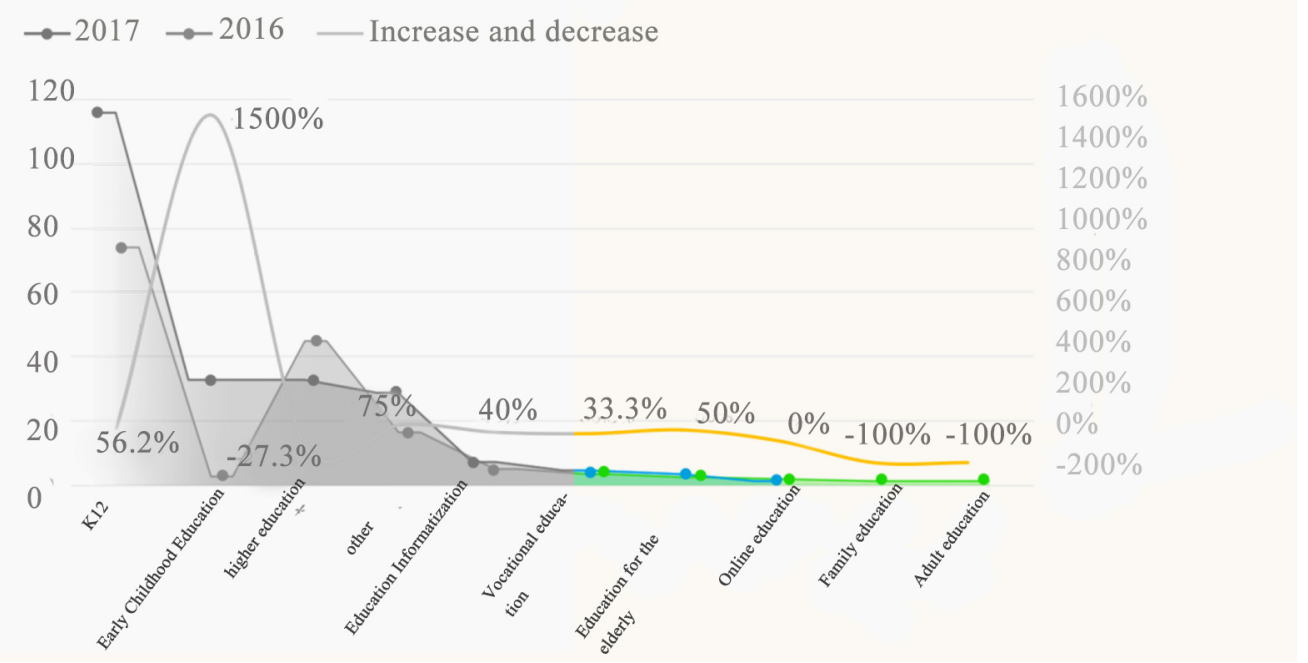

Figure 11. 2016-2017 classification statistics of education policy news.

It can be seen from the above statistics that STEAM education is in the stage of gradual development in China. Through years of exploration and experience accumulation, more and more initiatives have been implemented to provide a good development environment for the localization of STEAM education. However, at present, the development of STEAM education in primary and secondary schools in China is faced with the lack of macro system planning, weak teachers, and the lag of curriculum resources and environmental construction. There are still many areas for improvement [40]. The specific performance relates to the contradiction between the institutional team, curriculum, case accumulation, user expectations, and market demand. This has led to the inability of the organization to establish its own brand, win the mind of the user, and carry out rapid promotion. 


\section{Discussion}

In order to solve the problems related to the curriculum development difficulties, lack of teaching resources, and market promotion difficulties faced by STEAM educational institutions at this stage, this paper proposes four core competitiveness training strategies (Figure 12).

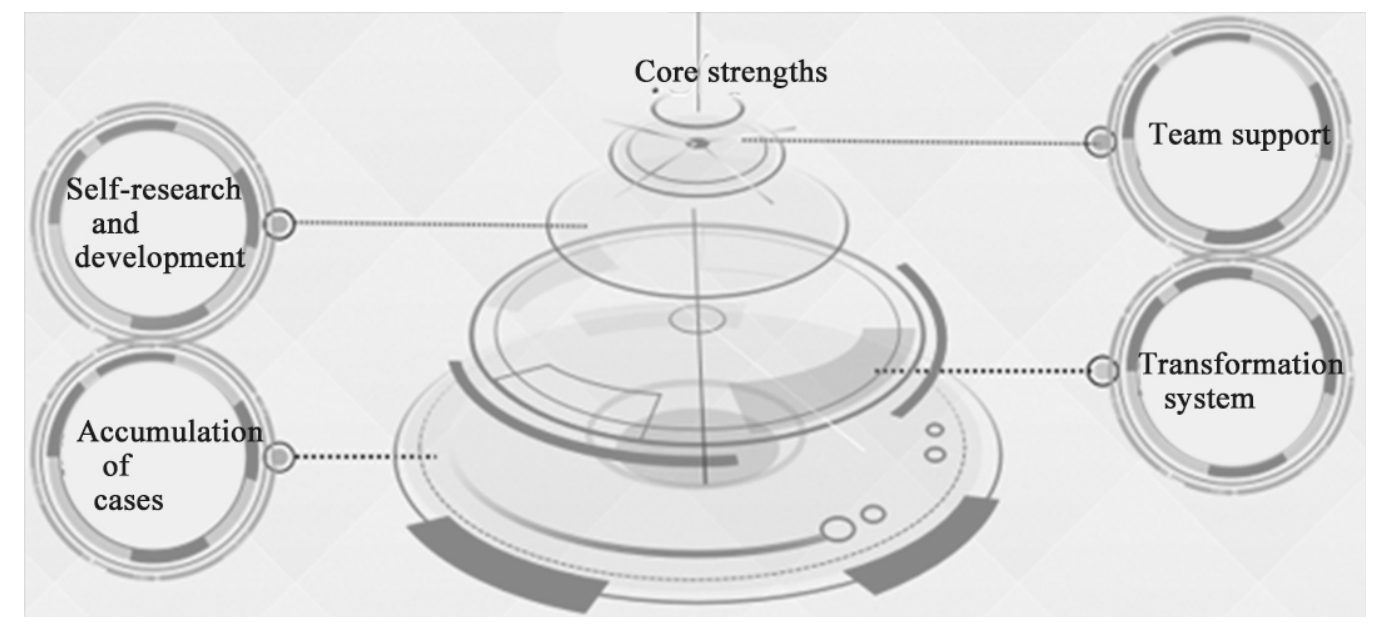

Figure 12. Four core competitiveness training strategies.

In order to improve teaching and research capabilities, team building is essential. This paper proposes a gradient team building plan, which needs to reflect the team's integration and development from both professional and senior aspects. This involves inviting domestically renowned integrated innovation education experts as team curriculum research and development consultants to control the progress and direction of research and development from the macro level and professional perspective. At the same time, the R\&D team includes undergraduate and postgraduate students covering engineering, science, math, physics, biology, and business in order to ensure the thickness of the team development.

The second is to develop the ability of independent research and development. This involves learning the mature teaching courses in the current stage of the market to find out feasible research and development ideas, and then combining the advantages of the team and the accumulation of content to carry out the course upgrade. At the same time, we should also pay attention to the development of independent curriculum brands in combination with regional development trends, regional unique characteristics, and the advantages of the research and development team's university. Take the operation of the Qingdao area as an example. The team consists of students from China University of Petroleum (East China) and other top-ranking colleges. In the course of curriculum development, we focus on the curriculum development of the "blue-yellow economy" and the topics of petroleum, geology, and the ocean.

The third is the transformation mechanism. This paper proposes a high-precision project transformation mechanism, which focuses on the transformation of scientific research topics. To a certain extent, colleges and universities represent the level of scientific research and development, and universities can reach the most advanced science and technology fields in the society, and predict the direction of science and technology development that is required for social development in the future. In the process of cultivating innovative talents, the cultivation of their vision and pattern is also very important [41]. Focusing on the transformation of scientific research topics, the transformation of advanced technology that is "unreachable" into a cognitive curriculum will help participants understand the development trend in advance and clarify future goals.

Finally, we accumulate cases. In the process of curriculum development, we must pay attention to the timely verification of course effectiveness [42]. This paper proposes two major verification channels and methods through practice. The first is the "4:30 public welfare activities". The 4:30 
class is an emerging hosting model recognized by the state. Through utilizing the joint community to create 4:30 classroom activities, we use the practice to verify the effectiveness of the course, and thus obtain course feedback. The second is to cooperate with the school to carry out the integration of innovative education activities. The authors set up "Little Scientists in Action" in three schools in Qingdao. Organizing by school can improve students' attention and participation, and thus obtain better verification data.

\section{Conclusions}

This paper analyzes three key issues in China's future sustainable development: severe population burden, economic transformation, and slow education reform, and put forward their core pain points. Through summarizing and analyzing the core pain points of the three problems, the root causes of the three problems are the lack of innovation ability and innovative talents, and the low scientific and technological literacy levels of a large number of industrial workers. It is concluded that the promotion of the concept of innovation ability based on multidisciplinary integration is imperative in China.

In view of the current situation of China's inadequate innovation, this paper analyzes the deep-seated reasons for the inadequate innovation and lack of innovative talents by using a multidimensional analysis of the status quo. Behind the slow implementation of STEAM education in China is huge population pressure and deep-rooted traditional educational concepts, which make the changes in educational status face enormous difficulties and challenges.

Combined with a literature review and analysis, the STEAM concept plays an important role in the future of China. Through typical case and practice analysis of the STEAM concept, this paper summarizes the STEAM literacy and curriculum types, the relationship between various disciplines, and the specific teaching implementation process. It is concluded that the STEAM concept is infiltrated with integrated innovation in terms of curriculum, subject integration methods, and teaching methods. The concept of training can play an important role in solving the three core issues of China at this stage. In order to spread good ideas faster, more attention should be paid to the importance of technology and humanities in the STEAM concept.

Faced with the contradiction between the slow implementation of STEAM education and the lack of innovative talent training modes in China, this paper puts forward some specific strategies to promote the implementation of STEAM education in China by analyzing the experience and lessons of teacher-led, knowledge-based education modes and education reform in Chinese primary and secondary schools. In order to promote the development of STEAM education in mainstream schools and form the implementation mode of the mutual promotion of STEAM education in and out of class, the ecosphere of extracurricular quality education training institutions should be improved by solving the problems related to the lack of teachers and difficulties in curriculum content research and development.

Finally, in order to verify the status quo of the STEAM concept, this paper combines the future world sustainable development requirements and the survey data to analyze the following. The existing organization has a single training content; in order to solve this problem, combined with practical experience, four core competitiveness training strategies were proposed. (1) The first is gradient team building. In team composition, we must pay attention to the integration of members in multiple fields and age groups in order to ensure the team's inheritance. (2) The second is advantageous independent research and development; we must learn to combine the geographical advantages, academic background advantages, and the professional knowledge of the research team to conduct research and development, and form barriers to curriculum competition. (3) The third is a high-precision project transformation mechanism; through cooperation with university research institutions and high-tech enterprises, we can master the most advanced technical information of the era's development, and carry out cognitive curriculum transformation to ensure the novelty and rapid iteration of the curriculum. (4) Two methods of course verification-the activities of "4:30 Science Classroom" and "Little Scientists in Action"- verify the effectiveness of the course. 
Author Contributions: X.W. and W.X. make the investigation. and analyzed the data and contributed materials/analysis tools. L.G. provided the data resources and make the Supervision. W.X. wrote the original draft, X.W. conceived the experiments, reviewed the paper and modified the draft. All authors read and approved the final manuscript.

Funding: This research received no external funding.

Acknowledgments: This research was funded by [The Shandong Provincial Key Research and Development Foundation, China], grant number [2017GSF218051]; [The Basic Research Business Fees of Central Colleges and Universities, China], grant number [18CX02111A]; [The Research Teaching Reform Project of China University of Petroleum (East China)], grant number [YK201606].

Conflicts of Interest: The authors declare no conflict of interest.

\section{References}

1. Li, Y. Research on the Countermeasures of Talent Cultivation in Colleges and Universities in China under the Background of New Industrialization; Nanchang University: Nanchang, China, 2007.

2. Yan, X.; Xie, J.; Li, Z. Application of Innovative Talents Cultivation and Practice Teaching Reform. Educ. Rev. 2009, 1, 48-50.

3. Tian, C. Research on the Effectiveness Strategy of High School Ideological and Political Classroom; Central China Normal University: Wuhan, China, 2014.

4. Shi, Z. On the Information Literacy of Middle School Students. Sel. Works Little Writ. 2015, $27,185$.

5. Jin, B. Research on the New Normal of China's Economic Development. China Ind. Econ. 2015, 1, 5-18.

6. Zhao, D.X.; He, B.J.; Meng, F.Q. The green school project: A means of speeding up sustainable development? Geoforum 2015, 65, 310-313. [CrossRef]

7. 13th Five-Year National Science and Technology Talent Development Plan. Available online: http://kjc.lvu. edu.cn/7a/9f/c453a31391/page.htm (accessed on 19 Novemebr 2018).

8. Li, Y.; Zhang, X. "New Normal”: The Logic and Prospect of Economic Development. Econ. Res. J. 2015, 50, 4-19.

9. Chen, Z.; Jiang, Q.; Feng, F.; Ma, H. Research on the Cultivation Mode of Graduate Students' Innovative Ability Based on Disciplinary Intersection. J. Chang. Railw. Univ. 2010, 11, 213-214.

10. Liu, X. How to carry out STEAM Education in American primary and secondary schools? Fujian Educ. 2018, 15, 35-37.

11. Li, X.; Gao, H.; Zou, J.; Wan, K. The Change of STEAM Education to Maker Education in the Background of "Internet +"-From Project-Based Learning to Cultivation of Innovation Ability. J. Distance Educ. 2016, 34, 28-36.

12. Wang, X.; Wang, W.; Sun, H. From STEM to STEAM: The Road to British Education Innovation. Comp. Educ. Res. 2017, 39, 3-9.

13. Chen, Y. STEAM is playing the discipline "cross-border". Era Innov. 2016, 8, 10-12.

14. Wang, J.; Wu, Y. Reflection and Innovation Path of STEAM Education Application in the Age of "Internet +". J. Distance Educ. 2016, 35, 90-97.

15. Dong, Y. Research on STEM Learning Interests of College Students in China; Southeast University: Nanjing, China, 2016.

16. Gao, Y.; Shi, B. The Integration of Maker Education and STEAM Education from the Perspective of Interdisciplinary Innovation. J. East China Norm. Univ. 2017, 35, 47-53.

17. Yang, X.; Li, Y. The Value Potential and Controversy of Maker Education. Mod. Distance Educ. Res. 2015, 2, 23-34.

18. Fu, Z. The space and ecological construction of creative space for Maker Education. Mod. Educ. Technol. 2015, $25,18-26$.

19. Song, L. Cultivation of Students' Creative Thinking: From STEAM Education to Maker Education. J. Hetian Teach. Coll. 2017, 36, 82-87.

20. Huang, R. STEM Education: Focus on the future of talent training. Today Educ. 2017, 10, 10-13.

21. Zhao, Z. STEM Education Series in Primary and Secondary Schools. Glob. Educ. Outlook 2016, 45, 129.

22. Sun, J.; Wu, Y.; Ren, Y. Innovation in 3D Printing Education: Maker Space, Innovation Lab and STEAM. Mod. Distance Educ. Res. 2015, 4, 96-103. 
23. Zhao, H.; Lu, X. Carrying out STEAM Education to improve students' ability to innovate-Interview with Professor G. Yakmen, a well-known scholar of STEAM Education in the United States. Open Educ. Res. 2016, 22, 4-10.

24. He, S. Research on the development standards of the three-dimensional expansion curriculum system of primary and middle schools under the concept of "learning talented people". New Courses 2016, 6, 30-32.

25. Chen, J. On the Course of Teacher Operation. Mod. Prim. Second. Educ. 2006, 8, 17-19.

26. Zhou, H. Practice and Exploration of General Education Research Volume 2; China Folk Art Publishing House: Beijing, China, 2006.

27. Shi, Y. Research on the Design of Junior Middle School Physics Curriculum Based on STEAM Concept; Guangxi Normal University: Guilin, China, 2017.

28. Cao, B. Analysis of the Problems in Deepening the Reform of Compulsory Education Curriculum. Teach. Mon. 2016, 10, 3-7.

29. Zhu, X. How to properly cultivate students' scientific literacy in Chinese classroom teaching. Extracurricular Chin. 2014, 6, 45.

30. Jiao, C.; Chang, S. On Cultural Quality Education and Cultivation of Innovative Talents in Colleges and Universities; Beijing University of Technology: Beijing, China, 2011.

31. He, B.J.; Zhao, D.X.; Zhu, J.; Darko, A.; Gou, Z.H. Promoting and implementing urban sustainability in China: An integration of sustainable initiatives at different urban scales. Habitat Int. 2018, 82, 83-93. [CrossRef]

32. Wang, X. Industrial 4.0: Intelligent industrial. Internet Things Technol. 2013, 3, 3-4.

33. Yang, S. "Made in China 2025": Local Advancement and Policy Dilemma. China Open. J. 2015, 6, 65-69.

34. Zhu, C. The New Situation of World Economic Development and the Construction of "One Belt, One Road". Pac. J. 2017, 25, 55-67.

35. Fei, Y.; Zhao, N.; Zhen, H. Discussion on the impact of global new technology revolution on the future shipping industry and its development trend. Pr. Foreign Econ. Relations Trade 2017, 10, 22-25.

36. Li, Z. STEAM: The Integration of Science, Technology, Engineering, Art and Mathematics. Shanghai Educ. 2013, 32, 44-47.

37. Wang, X.; Li, T. Study on the Cultivation Mechanism of Interdisciplinary Innovative Talents in Universities from the Perspective of Collaborative Innovation. Guid. Sci. Educ. 2017, 1, 40-41.

38. Chen, B.; Fu, M. Research on the status quo and countermeasures of humanities education for science and engineering graduates. Shandong Trade Unions' Trib. 2016, 22, 128-130.

39. Yu, S. The Construction of the Core Literacy Framework System of Chinese Students' Physical Education Discipline. J. Phys. Educ. 2017, 24, 5-9.

40. Hu, P.; Jiang, J.; Chen, Z. The Realistic Problems and Path Choice of STEAM Education Development in Primary and Secondary Schools in China. Mod. Educ. Technol. 2016, 26, 22-27.

41. Wang, K.; Zhu, Y. Innovation-driven development and reform of talent training mode in local colleges and universities. J. Shenyang Norm. Univ. 2016, 40, 81-84.

42. Dai, J. On the Transformation of Current Primary and Secondary School Curriculum Operation Mechanism in China; Shanghai Normal University: Shanghai, China, 2007.

(C) 2018 by the authors. Licensee MDPI, Basel, Switzerland. This article is an open access article distributed under the terms and conditions of the Creative Commons Attribution (CC BY) license (http:// creativecommons.org/licenses/by/4.0/). 